\title{
Effects of Solvents on Total Phenolic Content and Antioxidant Activity of Ginger Extracts
}

\author{
Dessie Ezez ${ }^{1}$ and Molla Tefera $\mathbb{i}^{2}$ \\ ${ }^{1}$ Department of Chemistry, Arba Minch University, P. O. Box 21, Arba Minch, Ethiopia \\ ${ }^{2}$ Department of Chemistry, University of Gondar, P. O. Box 196, Gondar, Ethiopia
}

Correspondence should be addressed to Molla Tefera; mollatef2001@gmail.com

Received 4 November 2020; Revised 25 April 2021; Accepted 28 April 2021; Published 4 May 2021

Academic Editor: Massimiliano F. Peana

Copyright (c) 2021 Dessie Ezez and Molla Tefera. This is an open access article distributed under the Creative Commons Attribution License, which permits unrestricted use, distribution, and reproduction in any medium, provided the original work is properly cited.

\begin{abstract}
Ginger (Zingiber officinale) is a popular spice which is used for the treatment of different gastrointestinal and inflammatory discomfort. In the present study, the total phenolic content (TPC) and antioxidant activity of ginger extract using four solvents (ethanol, methanol, acetone, and ethyl acetate) were determined. Among the four solvents, methanol extract showed the maximum phenolic content (1183.813 mg GAE/100 g at Ayikel and $1022.409 \mathrm{mg}$ GAE/100 g at Mandura) and the least phenolic content was found in acetone extract (748.865 mg GAE/100 g at Ayikel and 690.152 mg GAE/100 g at Mandura). In addition, the highest DPPH radical scavenging activity (84.868\% at Ayikel and $82.883 \%$ at Mandura) was observed in methanol. However, acetone showed the least DPPH radical scavenging activity (73.864\% at Ayikel and 70.597\% at Mandura). Antioxidant activities of ginger extracts were also expressed as $\mathrm{IC}_{50}$ values, and acetone extract has maximum $\mathrm{IC}_{50}$ value $(0.654$ and $0.812 \mathrm{mg} / \mathrm{mL})$ followed by ethyl acetate and ethanol, while being the lowest for methanol $(0.481$ and $0.525 \mathrm{mg} / \mathrm{mL})$. The result of this study showed that extraction solvents significantly affected the total phenolic content and antioxidant activities of ginger. Thus, ginger can be regarded as promising candidates for natural sources of antioxidants with a high value of phenolic contents.
\end{abstract}

\section{Introduction}

Natural bioactive compounds especially plant sources have been investigated for their characteristics and health effects [1]. Many spices such as cardamom, long pepper, black cumin, ginger, bishops weed, and coriander are highly cultivated in Ethiopia over many years. However, ginger (Zingiber officinale Roscoe) is cultivated in many places of the country than any other spices [2]. The refreshing aroma and pungent taste makes ginger an essential ingredient in most world cuisine and food processing industry [3]. Besides, ginger has been employed as an alternative medicine around the world for antiarthritic activity [4], protects against gastrointestinal ulcers, improves blood circulation, lowers blood glucose in the treatment of diabetes [5], and diarrhea [6].

Numerous active ingredients are present in ginger such as terpenes (sesquiterpene hydrocarbons), alkaloids, and polyphenols [7].
Phenolic compounds are associated with a high number of biological activities and one with special interest is their antioxidant capacity [8] and may help to protect the cells against the oxidative damage caused by free radicals $[9,10]$. Antioxidant activities of ginger have been identified by many researchers $[11,12]$. Several studies revealed that ginger has showed antioxidant activity against lipid oxidation and oxidative stress $[13,14]$.

There are many techniques to extract total polyphenols from plants, such as Soxhlet extraction, maceration, supercritical fluid extraction, subcritical water extraction, and ultrasound-assisted extraction. Due to simplicity and low economic outlay, classical extraction methods are most commonly used for isolating these compounds in many samples. For successful separation and determination of biologically active compounds from plant material, it mainly depends on the type of solvent used in the extraction procedure. Extraction with water alone was not as effective 
as extraction with aqueous solution of organic solvents such as ethanol, methanol, diethyl ether, chloroform, ethyl acetate, and $n$-butanol [15-17].

Taking into account all these aspects, the present study was undertaken with the purpose of determining the effects of aqueous solution of different solvents (ethanol, methanol, acetone, and ethyl acetate) on the total polyphenol and antioxidant capacity of ginger extracts collected from local markets in Ayikel and Mandura towns, Ethiopia.

\section{Materials and Methods}

2.1. Chemicals. DPPH (2,2-diphenyl-1-picrylhydrazyl), ascorbic acid, gallic acid, sodium carbonate, Folin-Ciocalteu reagent were purchased from Sigma-Aldrich (Mumbai, India). The solvents acetone, ethanol, methanol, and ethyl acetate were obtained from Merck (Darmstadt, Germany). All the reagents and chemicals used were of analytical reagent grade and were acquired from commercial sources. Deionized water was used for sample preparation, dilution, and rinsing apparatus prior to analysis.

2.2. Instruments. Microprocessor UV-Vis double beam spectrophotometer (Abron, India), refrigerator (LR 1602, England), vortex mixer (Abron, India), scalpel, grinder, magnetic stirrer, measuring cylinder, Whatman filter paper (No. 42) micropipettes, electronic balance (CTG 1200), separatory funnel, and aluminum foil.

2.3. Sample Collection and Preparation. Three kilograms of fresh ginger rhizome samples $(n=6)$ with no apparent physical or microbial damages were collected randomly from local markets of Ayikel and Mandura town, Ethiopia. The collected samples from each study area were pooled together and mixed well to have one bulk sample from each site. The ginger samples were washed with tap water and distilled water and finally were peeled. The peeled samples were then sliced separately into pieces using scalpel and dried at room temperature for several days. Finally, the dried samples were ground to a fine powder using grinder and then sieved using mesh and stored in until required for extraction.

2.4. Extraction of Ginger Samples. Solvent extractions are the most commonly used procedures to extract polyphenol from plant materials due to their ease of use, efficiency, and wide applicability. For the present study, an aqueous solution of methanol, acetone, ethanol, and ethyl acetate $(1: 4$, water, solvent, $v, v)$ was used as solvent to extract total polyphenol contents from the samples. One gram $(1.0 \mathrm{~g})$ of ginger was weighed and mixed with $20 \mathrm{~mL}$ of organic solvents (acetone, methanol, ethanol, and ethyl acetate) into different $100 \mathrm{~mL}$ conical flasks and covered with aluminum foil. The solution was magnetically stirred at $900 \mathrm{rpm}$ for $24 \mathrm{~h}$ at room temperature. The supernatant was collected, filtered, and finally kept in the refrigerator at $4^{\circ} \mathrm{C}$ until further analysis.
2.5. Total Phenolic Content. The concentration of total phenol present in ginger extracts was determined by Folin-Ciocalteu (FC) reagent method described by Munro et al. [18]. In brief, $0.5 \mathrm{~mL}$ of solvent extracts of each ginger sample was mixed with $2.5 \mathrm{~mL}$ of $10 \%$ Folin-Ciocalteu reagent. After $5 \mathrm{~min}$ in the dark, $2 \mathrm{~mL}$ of $7.5 \%$ sodium carbonate was added. The solution was agitated with a vortex mixer for a min before incubation in the dark for $1 \mathrm{~h}$ at room temperature. The absorbance was determined using a UVVis spectrophotometer at $760 \mathrm{~nm}$. The calibration curve was established using gallic acid (5-150 mg/L). The phenolic content was expressed as milligram gallic acid equivalents per $100 \mathrm{~g}$ dry extract (mg GAE/100 g). All determinations were performed in triplicate.

2.6. Antioxidant Capacity. The antioxidant activity of ginger extracts was evaluated using the method described by Koleva et al. [19]. In brief, $1.0 \mathrm{~mL}$ of sample extracts at various concentrations $(0.2-1.5 \mathrm{mg} / \mathrm{mL})$ was added to $2 \mathrm{~mL}$ of $0.040 \mathrm{~g} / \mathrm{L} \mathrm{DPPH}$ in methanol solution. The test tube was incubated in the dark for about $30 \mathrm{~min}$ at room temperature. Ascorbic acid was used as positive control. Different concentrations ranging from 0.2 to $1.5 \mathrm{mg} / \mathrm{mL}$ of ascorbic acid were used for constructing calibration curve, and $\mathrm{IC}_{50}$ values were calculated.

The antioxidant activity was recorded spectrophotometrically at an absorbance of $517 \mathrm{~nm}$, and the percentage inhibition of radicals was calculated using the following formula:

$$
\% \text { inhibition }=\left[\frac{A_{\mathrm{bl}}-A_{\mathrm{sa}}}{A_{\mathrm{bl}}}\right] \times 100,
$$

where $A_{\mathrm{bl}}$ is the absorbance of the blank DPPH solution without ginger extract and $A_{\mathrm{sa}}$ is the absorbance of sample extracts with DPPH. All antioxidant determinations were performed in triplicate.

2.7. Statistical Analysis. All the experiments were carried out in triplicate, and the values were expressed as mean\pm standard deviation, and the data were analyzed statistically using the IBM SPSS software (version 20). An analysis of variance was performed by one-way ANOVA, and significant differences between the means due to composition of extraction solvent were determined by Tukey's HSD (homogeneous subset difference) test at the significance level $p=0.05$.

\section{Results and Discussion}

3.1. Total Phenolic Content. The total phenolic contents were determined by plotting the standard calibration curve of different concentrations of gallic acid using a spectrophotometer at $760 \mathrm{~nm}$. The values of TPC were calculated as gallic acid equivalents (GAE) per 100 gram of dry weight.

The amount of total phenolic content in ginger samples collected from Ayikel and Mandura was influenced significantly by extracting solvent $(p<0.05)$, and the contents 
were varied within the range of 690.152 to $1183.813 \mathrm{mg}$ of GAE/100 g of dry weight for acetone and methanol, respectively. Among the solvents, methanol was the most efficient extracting solvent for TPC, followed by ethanol, ethyl acetate, and acetone, indicating that the TPC extracted in ginger was higher in polar solvents compared with less polar solvents (Table 1). The variations in the extract yields from ginger using different solvents might be explained by the difference in polarity of different compounds in the samples $[20,21]$.

Between the two study areas, the higher TPC was found in a ginger sample collected from Ayikel in all extracts. The difference in the quantity of TPC may be attributable to different intrinsic and extrinsic factors, including cultivars, type of soil and growing conditions, maturity state, and harvest conditions $[22,23]$.

3.2. Antioxidant Activity. Antioxidant activity of ginger extract was evaluated using ascorbic acid as standard. It is one of the greatest antioxidant compound known by scavenging the stable radical of 1, 1-diphenyl-2-picryl-hydrazyl (DPPH).

The antioxidant values obtained are presented in Table 2. From the data, it is evident the Ayikel ginger samples showed higher value of DPPH (\% inhibition) and TPC as compared to Mandura. The value for DPPH (\% inhibition) activity of the extracts can be ranked as methanol extract $>$ ethanol extract $>$ ethyl acetate extract $>$ acetone extract. In addition, the current finding revealed that antioxidant activity was significantly correlated with the phenolic content. Except acetone and ethyl acetate extracts, there were significant differences $(p<0.05)$ of DPPH radical scavenging abilities between all extracts. As with TPC value, it was observed that methanol extract owned the highest DPPH radical scavenging ability, followed by ethanol, ethyl acetate, and acetone. The radical scavenging activities of ginger were close to the positive control, i.e., ascorbic acid with \% inhibition of $89.75 \pm 0.361$.

The result was in agreement with those findings reported in literature, where the phenolic content and antioxidant activity were influenced by extracting solvents. In addition, the current finding revealed that a highest DPPH radical scavenging activity of ginger extract was obtained when methanol was used for extracting solvent $[1,24,25]$.

The half maximal inhibitory concentration $\left(\mathrm{IC}_{50}\right)$ is defined as the amount of antioxidant that causes decrease in the DPPH concentration by $50 \%$ [26]. The $\mathrm{IC}_{50}$ value was calculated from the linear regression plots of percentage inhibition (\% DPPH scavenging activity) against concentration of ginger extracts. As depicted in Table 3, the $\mathrm{IC}_{50}$ values of Ayikel ranged from 0.481 to $0.654 \mathrm{mg} / \mathrm{mL}$ for methanol and acetone extracts, respectively. Similarly, it was found that acetone extracts owned the highest $\mathrm{IC}_{50}$ value followed by ethyl acetate, ethanol, and methanol extracts in Mandura ginger. This implies that the concentration of acetone extract required to decrease the initial concentration of DPPH solution by $50 \%$ is $0.654 \mathrm{mg} / \mathrm{mL}$, whereas for methanol extract, it is $0.481 \mathrm{mg} / \mathrm{mL}$. The result showed that the $\mathrm{IC}_{50}$ value is inversely related to its antioxidant capacity.
TABle 1: Total phenolic content of ginger from Ayikel and Mandura locations extracted with different solvents.

\begin{tabular}{lcc}
\hline \multirow{2}{*}{ Solvents } & \multicolumn{2}{c}{ TPC $(\mathrm{mg} \mathrm{GAE} / 100 \mathrm{~g})^{*}$} \\
& Ayikel & Mandura \\
\hline Ethanol & $1009.917 \pm 0.140^{\mathrm{a}, \mathrm{x}}$ & $941.847 \pm 0.177^{\mathrm{e}, \mathrm{y}}$ \\
Ethyl acetate & $899.041 \pm 0.121^{\mathrm{b}, \mathrm{x}}$ & $778.806 \pm 0.253^{\mathrm{f}, \mathrm{y}}$ \\
Methanol & $1183.813 \pm 0.418^{\mathrm{c}, \mathrm{x}}$ & $1022.409 \pm 0.265^{\mathrm{g}, \mathrm{y}}$ \\
Acetone & $748.865 \pm 0.210^{\mathrm{d}, \mathrm{x}}$ & $690.152 \pm 0.214^{\mathrm{h}, \mathrm{y}}$ \\
\hline
\end{tabular}

Values represented mean \pm S.D. of three parallel measurements $(p<0.05)$. For each solvent extracts, values in the same column for each sample followed by different letters $(\mathrm{a}-\mathrm{h})$ are significantly different $(p<0.05)$. For each plant sample, values in same row for each solvent followed by a different letter $(\mathrm{x}, \mathrm{y})$ are significantly different $(p<0.05)$ by Tukey's multiple range tests.

It was elucidated that the methanol extracts showed highest antioxidant activities than the other solvents. However, the $\mathrm{IC}_{50}$ values regarding different solvents used for extraction were as follows: acetone $>$ ethyl acetate $>$ ethanol $>$ methanol. The results are similar to those reported by $[17,27]$, where a lowest DPPH radical scavenging activity of a plant extract had the highest $\mathrm{IC}_{50}$.

In our study, ascorbic acid was used as the positive control; with an $\mathrm{IC}_{50}$ value estimated at $0.239 \mathrm{mg} / \mathrm{mL}$, while the $\mathrm{IC}_{50}$ values of the ginger extracts ranged from 0.481 to $0.812 \mathrm{mg} / \mathrm{mL}$. This indicates that the extracts are slightly potent inhibitors in comparison with ascorbic acid.

\subsection{Comparison of the Current Study with Results from Other} Countries. There are some reports from different countries on the analysis of the phenolic contents and antioxidants activities of ginger. It is important to compare the results obtained in this study with the values reported in other countries. This comparison helps to identify the differences in composition of samples between countries.

As shown in Table 4, the total phenol contents of ginger extract obtained in this study are higher than those reported by Sharif and Bennett [28] and Adel and Prakash [29].

However, methanol extract reported by Ghorab et al. [30] was found to be higher than the results of this study. The total polyphenol of methanol extract was found to be comparable with the results reported by Mohd and Muhd [31]. Besides, total phenol content of acetone and ethyl acetate extract reported by Mohd and Muhd [31] and Ghasemzadeh et al. [32], respectively, was found to be higher than the results obtained in this study at both study sites.

The antioxidant properties of ginger were also compared with the reports from other countries. As shown in Table 5, the antioxidant activities were found to be slightly higher than those reported by Ghasemzadeh et al. [1,32] and Mohd and Muhd [31]. However, the results of present study were in agreement with the reported values by Ghorab et al. [30] and Sharif and Bennett [28]. The differences in the total phenol contents and antioxidant activity of this study with previously reported values were attributed to several factors such as the difference in plant variety, the method and conditions of extraction (temperature and time), environmental conditions, degree of ripeness, plant variety, and sun exposure 
TABLE 2: \% inhibition of ginger extract.

\begin{tabular}{lcc}
\hline \multirow{2}{*}{ Solvents } & \multicolumn{2}{c}{$\begin{array}{c}\text { Samples } \\
\text { Ayikel }\end{array}$} \\
\hline Ethanol & $82.108 \pm 0.416^{\mathrm{a}, \mathrm{x}}$ & $77.975 \pm 0.297^{\mathrm{d}, \mathrm{y}}$ \\
Ethyl acetate & $81.398 \pm 0.297^{\mathrm{b}, \mathrm{x}}$ & $75.967 \pm 0.391^{\mathrm{e}, \mathrm{y}}$ \\
Methanol & $84.868 \pm 0.293^{\mathrm{c}, \mathrm{x}}$ & $82.883 \pm 0.216^{\mathrm{f}, \mathrm{y}}$ \\
Acetone & $73.864 \pm 0.418^{\mathrm{b}, \mathrm{x}}$ & $70.597 \pm 0.332^{\mathrm{e}, \mathrm{y}}$ \\
\hline
\end{tabular}

For each solvent extracts, values in the same column for each sample followed by a different letter $(\mathrm{a}-\mathrm{f})$ are significantly different $(p<0.05)$. For each plant sample, values in same row for each solvent followed by a different letter $(\mathrm{x}, \mathrm{y})$ are significantly different $(p<0.05)$ by Tukey's multiple range tests.

TABLE 3: $\mathrm{IC}_{50}(\mathrm{mg} / \mathrm{mL})$ values of ginger by different solvent extracts.

\begin{tabular}{lcc}
\hline \multirow{2}{*}{ Solvents } & \multicolumn{2}{c}{$\mathrm{IC}_{50}(\mathrm{mg} / \mathrm{mL})^{*}$} \\
& Ayikel & Mandura \\
\hline Ethanol & $0.499 \pm 0.021$ & $0.548 \pm 0.045$ \\
Ethyl acetate & $0.501 \pm 0.034$ & $0.653 \pm 0.028$ \\
Methanol & $0.481 \pm 0.015$ & $0.525 \pm 0.017$ \\
Acetone & $0.654 \pm 0.054$ & $0.812 \pm 0.06$ \\
\hline
\end{tabular}

${ }^{*}$ Values represented as mean \pm S.D.

TABle 4: Comparison of total phenol content of ginger with that reported in the rest of the world (mg GAE/100 g).

\begin{tabular}{lcccc}
\hline Ethanol & Methanol & $\begin{array}{c}\text { Ethyl } \\
\text { acetate }\end{array}$ & Acetone & References \\
\hline 263 & 148 & NA & 216 & $\begin{array}{c}\text { Sharif and Bennett, } \\
2016\end{array}$ \\
NA & NA & 1022 & NA & $\begin{array}{c}\text { Ghasemzadeh et al., } \\
2010\end{array}$ \\
NA & 565 & 510 & 325 & $\begin{array}{c}\text { Adel and Prakash, } \\
2010\end{array}$ \\
NA & 9520 & NA & NA & $\begin{array}{c}\text { Ghorab et al., 2010 } \\
\text { Mohd and Muhd, } \\
2016\end{array}$ \\
NA & 1340 & NA & 1110 & $\begin{array}{c}\text { This study (Ayikel) } \\
1009.917\end{array}$ \\
1183.813 & 899.041 & 748.865 & $\begin{array}{c}\text { This } \\
\text { This study (Mandura) }\end{array}$ \\
\hline
\end{tabular}

TABLE 5: Comparison of \% inhibition of ginger with that reported in the rest of the world.

\begin{tabular}{|c|c|c|c|c|}
\hline Ethanol & Methanol & $\begin{array}{l}\text { Ethyl } \\
\text { acetate }\end{array}$ & Acetone & References \\
\hline 93 & 82.2 & NG & 87.1 & $\begin{array}{l}\text { Sharif and bennett, } \\
2016\end{array}$ \\
\hline NA & 51.48 & NG & 49.22 & $\begin{array}{c}\text { Ghasemzadeh et al., } \\
2011\end{array}$ \\
\hline NG & 51.41 & NG & NG & $\begin{array}{l}\text { Ghasemzadeh et al., } \\
2010\end{array}$ \\
\hline NG & 58.21 & NG & 56.18 & $\begin{array}{l}\text { Mohd and Muhd, } \\
2016\end{array}$ \\
\hline NG & 87.66 & NG & NG & Ghorab et al. 2010 \\
\hline 82.883 & 84.868 & 81.398 & 73.864 & This study (Ayikel) \\
\hline 77.975 & 82.883 & 75.967 & 70.597 & This study (Mandura) \\
\hline
\end{tabular}

$[17,33,34]$. For instance, the ginger studied by [28, 29] was extracted at $8 \mathrm{~h}$ and $3 \mathrm{~h}$, respectively.

\section{Conclusion}

According to the results, the yield and efficiency of the phenolic content extraction depend on the type and kind of the solvent which is being isolated. The highest concentration of phenolic compounds in the extracts was obtained using solvents of high polarity relative to the other solvents, and methanol extract manifested greater power of extraction for phenolic compounds from ginger rhizome.

The highest total phenolic content is $1183.813 \pm 0.418 \mathrm{mg}$ GAE/100 g DW for methanol extract, $1009.917 \pm 0.140 \mathrm{mg}$ GAE/100 g DW for ethanol extract for Ayikel samples, and $1022.409 \pm 0.265 \mathrm{mg} \mathrm{GAE} / 100 \mathrm{~g}$ DW for methanol extract, followed by $941.847 \pm 0.177 \mathrm{mg}$ GAE$/ 100 \mathrm{~g}$ DW for ethanol extract for Mandura samples. For total phenolic extraction from ginger, methanol was more efficient than ethanol, ethyl acetate, and acetone. Methanol extract has maximum antioxidant activity than all other solvents followed by ethanol extract.

\section{Data Availability}

The data used to support the findings of this study are included within the article.

\section{Conflicts of Interest}

The authors declare that they have no conflicts of interest.

\section{Acknowledgments}

The authors would like to extend their sincere appreciation to the Chemistry Department at University of Gondar for providing equipment for sampling and laboratory facilities for sample analysis.

\section{References}

[1] A. Ghasemzadeh, H. Jaafar, and A. Rahmat, "Effects of solvent type on phenolics and flavonoids content and antioxidant activities in two varieties of young ginger (Zingiber officinale Roscoe) extracts," Journal of Medicinal Plants Research, vol. 5, pp. 1147-1154, 2011.

[2] V. Hegde and S. Hegde, "An economic overview of ginger production in Ethiopia," International Journal of Science and Research, vol. 2012, pp. 2052-2054, 2012.

[3] S. K. Sanwal, N. Rai, J. Singh, and J. Buragohain, “Antioxidant phytochemicals and gingerol content in diploid and tetraploid clones of ginger (Zingiber officinale Roscoe)," Scientia Horticulturae, vol. 124, no. 2, pp. 280-285, 2010.

[4] T. Mangprayool, S. Kupittayanant, and N. Chudapongse, "Participation of citral in the bronchodilatory effect of ginger oil and possible mechanism of action," Fitoterapia, vol. 89, pp. 68-73, 2013.

[5] G. Oboh, A. Akinyemi, A. Ademiluyi, and S. Adefegha, "Inhibitory effects of aqueous extract of two varieties of ginger on some key enzymes linked to type-2 diabetes in vitro," Journal of Food and Nutrition Research, vol. 49, pp. 14-20, 2010. 
[6] K. An, D. Zhao, Z. Wang, J. Wu, Y. Xu, and G. Xiao, "Comparison of different drying methods on Chinese ginger (Zingiber officinale Roscoe): changes in volatiles, chemical profile, antioxidant properties, and microstructure," Food Chemistry, vol. 197, pp. 1292-1300, 2016.

[7] J. Bonilla, T. Poloni, R. V. Lourenço, and P. Sobral, "Antioxidant potential of eugenol and ginger essential oils with gelatin/chitosan films," Food Bioscience, vol. 23, pp. 107-114, 2018.

[8] S. Gouveia, P. C. Castilho, and P. Castilho, "Antioxidant potential of Artemisia argentea L'Hér alcoholic extract and its relation with the phenolic composition," Food Research International, vol. 44, no. 6, pp. 1620-1631, 2011.

[9] R. Breemen, Y. Tao, and W. Li, "Cyclooxygenase-2 inhibitors in ginger (Zingiber officinale)," Fitoterapia, vol. 82, pp. 38-43, 2011.

[10] B. Auddy, M. Ferreira, F. Blasina et al., "Screening of antioxidant activity of three Indian medicinal plants, traditionally used for the management of neurodegenerative diseases," Journal of Ethnopharmacology, vol. 84, no. 2-3, pp. 131-138, 2003.

[11] I. Stoilova, A. Krastanov, A. Stoyanova, P. Denev, and S. Gargova, "Antioxidant activity of a ginger extract (Zingiber officinale)," Food Chemistry, vol. 102, no. 3, pp. 764-770, 2007.

[12] M. Maizura, A. Aminah, and W. Aida, "Total phenolic content and antioxidant activity of kesum (Polygonum minus), ginger (Zingiber officinale) and turmeric (Curcuma longa) extract," International Food Research Journal, vol. 18, pp. 526-531, 2011.

[13] S. Singh, J. Patel, and D. Bachle, "A review on Zingiber officinale a natural gift," Journal of Pharmacology and Biological Science, vol. 5, pp. 508-525, 2014.

[14] T. M. Rababah, N. S. Hettiarachchy, and R. Horax, "Total phenolics and antioxidant activities of fenugreek, green tea, black tea, grape seed, ginger, rosemary, gotu kola, and ginkgo extracts, vitamin E, andtert-butylhydroquinone," Journal of Agricultural and Food Chemistry, vol. 52, no. 16, pp. 51835186, 2004.

[15] A. a. Al-Rifai, A. Aqel, T. Al-Warhi, S. M. Wabaidur, Z. A. AlOthman, and A. Y. Badjah-Hadj-Ahmed, "Antibacterial, antioxidant activity of ethanolic plant extracts of some convolvulus species and their DART-ToF-MS profiling," Evidence-Based Complementary and Alternative Medicine, vol. 2017, pp. 1-9, 2017.

[16] J. Boeing, E. Barizao, B. Silva, P. Montanher, V. Almeida, and J. Visentainer, "Evaluation of solvent effect on the extraction of phenolic compounds and antioxidant capacities from the berries: application of principal component analysis," Chemistry Central Journal, vol. 8, pp. 1-9, 2014.

[17] Q. D. Do, A. E. Angkawijaya, P. L. Tran-Nguyen et al., "Effect of extraction solvent on total phenol content, total flavonoid content, and antioxidant activity of Limnophila aromatica," Journal of Food and Drug Analysis, vol. 22, no. 3, pp. 296-302, 2014.

[18] B. Munro, Q. Vuong, A. Chalmers, C. Goldsmith, M. Bowyer, and C. Scarlett, "Phytochemical, antioxidant and anti-cancer properties of Euphorbia tirucalli methanolic and aqueous extracts," Antioxidants, vol. 4, no. 4, pp. 647-661, 2015.

[19] I. I. Koleva, T. A. Van Beek, J. P. H. Linssen, A. d. Groot, and L. N. Evstatieva, "Screening of plant extracts for antioxidant activity: a comparative study on three testing methods," Phytochemical Analysis, vol. 13, no. 1, pp. 8-17, 2002.

[20] N. Babbar, H. Oberoi, S. Sandhu, and V. Bhargav, "Influence of different solvents in extraction of phenolic compounds from vegetable residues and their evaluation as natural sources of antioxidants," Journal of Food Science and Technology, vol. 51, pp. 2568-2575, 20014.

[21] C. C. Denardin, G. E. Hirsch, R. F. da Rocha et al., "Antioxidant capacity and bioactive compounds of four Brazilian native fruits," Journal of Food and Drug Analysis, vol. 23, no. 3, pp. 387-398, 2015.

[22] C. Phang, S. Malek, H. Ibrahim, and N. Wahab, "Antioxidant properties of crude and fractionated extracts of Alpinia mutica rhizomes and their total phenolic content," African Journal of Pharmacy and Pharmacology, vol. 5, pp. 842-852, 2015.

[23] E. Jaffery, A. Brown, and N. Matusheski, "Antioxidant activity of ginger and identification of its active components," Journal of Food Composition Analysis, vol. 16, pp. 323-330, 2003.

[24] A. Dailey and Q. Vuong, "Effect of extraction solvents on recovery of bioactive compounds and antioxidant properties from macadamia (Macadamia tetraphylla) skin waste," Cogent Food and Agriculture, vol. 1, pp. 1-10, 2015.

[25] S. Zazouli, M. Chigr, and A. Jouaiti, "Effect of polar and nonpolar solvent on total phenolic and antioxidant activity of roots extracts of Caralluma europaea," Der Pharma Chemica, vol. 8, pp. 191-196, 2016.

[26] R. Tauheeda, A. Muhammad, and S. Tayyaba, "Antioxidant activity and phenolic content of Dodonaea viscose," Journal of the Serbian Chemical Society, vol. 77, pp. 423-435, 2016.

[27] A. Thouri, H. Chahdoura, A. El Arem, H. Omri, B. Hassin, and L. Achour, "Effect of solvents extraction on phytochemical components and biological activities of Tunisian date seeds (var. Korkobbi and Arechti)," BMC Complementary and Alternative Medicine, vol. 17, pp. 1-10, 2017.

[28] M. Sharif and M. Bennett, "The effect of different methods and solvents on the extraction of polyphenols in Zingiber officinale," Journal of Science and Engineering, vol. 78, pp. 49-54, 2016.

[29] S. Adel and J. Prakash, "Chemical composition and antioxidant properties of ginger root (Zingiber officinale)," Journal of Medicinal Plants Research, vol. 4, pp. 2674-2679, 2010.

[30] A. Ghorab, M. Nauman, F. Anjum, S. Hussain, and M. Nadeem, "Comparative study on chemical composition and antioxidant activity of ginger (Zingiber officinale) and cumin (Cuminum cyminum)," Journal of Agricultural and Food Chemistry, vol. 58, pp. 8231-8237, 2014.

[31] F. Mohd and T. Muhd, "The effect of different methods and solvents on the extraction of polyphenols in Zingiber officinale," Journal of Science and Technology, vol. 78, pp. 49-54, 2016.

[32] A. Ghasemzadeh, A. Rahmat, and R. Asmah, "Antioxidant activities, total phenolics and flavonoids content in two varieties of Malaysia young ginger (Zingiber officinale Roscoe)," Molecules, vol. 15, no. 6, pp. 4324-4333, 2010.

[33] P. Bagattoli, D. Cipriani, L. Mariano et al., "Phytochemical, antioxidant and anticancer activities of extracts of seven fruits found in the southern brazilian flora," Indian Journal of Pharmaceutical Sciences, vol. 78, pp. 34-40, 2016.

[34] C. Manach, A. Scalbert, C. Morand, C. Rémésy, and L. Jiménez, "Polyphenols: food sources and bioavailability," The American Journal of Clinical Nutrition, vol. 79, no. 5, pp. 727-747, 2004. 